\title{
172. Analysis of vibration propagation in the human body
}

\author{
Rafal Burdzik \\ Silesian University of Technology, Faculty of Transport, Katowice, Poland \\ E-mail: rafal.burdzik@polsl.pl
}

Received 4 September 2018; received in revised form 22 November 2018; accepted 1 December 2018 DOI https://doi.org/10.21595/jme.2018.20425

Check for updates

Copyright (C) 2018 Rafat Burdzik. This is an open access article distributed under the Creative Commons Attribution License, which permits unrestricted use, distribution, and reproduction in any medium, provided the original work is properly cited.

\begin{abstract}
The human vibration is a multi-disciplinary subject involving many disciplines. A special area in the field of vibration research is the transport system. The paper presents the results of preliminary tests, the aim of which was to analyze the propagation of vibrations forced by the movement of the vehicle floor on persons sitting in a car. During research vibration were registered in measurement nodes, in which the composition always included the signal of oscillation of the enforcing plate and specific locations on the human body. This paper presents results of vibration recorded on the extinction plate and on the head of the passenger.
\end{abstract}

Keywords: human vibration, sitting position, vibration propagation.

\section{Introduction}

Studies on the impact of vibrations on humans are conducted by numerous research centers. In the field of safety at workplace, many standards have been developed regarding this issue and the assessment of the permissible values of vibrations affecting humans. One of the standards that describes vibration is the ISO 2631 standard [5]. Its Polish equivalent is the PN-EN 14253 + A1: 2011 standard [6]. ISO 2631 is an international standard that describes test methodology and methods of protecting the human body exposed to vibrations. Also, EU provide legislation on vibration-exposed workers according to the European Directive 2002/44/EC on mechanical vibration [7].

A special area in the field of vibration research is the transport system [1-4]. Drivers and passengers are exposed to various types of vibrations, which depending on the severity and frequency affect the comfort of the traveler and also indirectly on safety. Vibrations affecting humans can cause imbalances, muscle pain, nausea, vomiting and dizziness. They very often resemble the symptoms of motion sickness. As it is described in [8] the sense of vibration (in scale from pleasure to pain) depends on many factors including characteristics of exposed person. Therefore, studies of human response to vibration are complicate.

Mechanical vibrations, as oscillatory motion, were divided into two types:

- General vibrations transmitted by legs, pelvis, back to the human body (WBV-whole-body vibration),

- Local vibrations, which are transmitted through the hands directly to the human body (HTW-hand-transmitted vibration).

The driver and passengers staying in the vehicle not only feel the vibrations caused by the inequality of the road or additional elements of its infrastructure (e.g. speed bumps), but also resulting from the working state of the vehicle e.g. vibrations transmitted by the engine, tires, exhaust system or transmission system [9-11]. It should be noted that people who are exposed to long vibration exposure in their daily work, e.g. machine operators, especially those using work vibrations (e.g. concrete compactors, rollers, drills, hammers) are at high risk for many diseases. Long-term occupational exposure to intense WBV is associated with an increased risk for disorders of the lumbar spine and the connected nervous system [12].

The knowledge on human vibration is a multi-disciplinary subject involving engineering, ergonomics, medicine, physics and many more disciplines [8]. Thus, if the task is to conduct 
complex analysis of human vibration it requires vide scope and detailed planning with takin into consideration many aspects [13].

\section{Research}

The aim of the research was to analyze the vibrations acting on a human being in a sitting position. As part of the experiments, tests were carried out at the station that allows forcing vertical movements in specific frequency bands. As a result, the effect of vibrations on the driver or passengers of the vehicle moving at a constant speed is simulated. A car seat is attached to the seat panel, which can be positioned in the longitudinal and transverse direction.

The research assumption was the registration of vibrations in measurement nodes, in which the composition always included the signal of oscillation of the enforcing plate and specific locations on the human body. This type of study enables analysis of response to a single frequency motion (sinusoidal vibration). Of course, vibration exposures encountered during driving are random but for the purpose of vibration propagation analysis this research method is suitable.

In order to make measurements, special sensor bands were made to record accelerations. During the tests, vibration acceleration signals were recorded in 3 orthogonal axes $(X, Y, Z)$. Due to the risks resulting from long-term vibration exposure, a short measurement cycle was adopted, which was about 1 minute for a given measuring node. Fig. 1 presents the research stand and the author during the tests with a set of sensors on the head mounted.

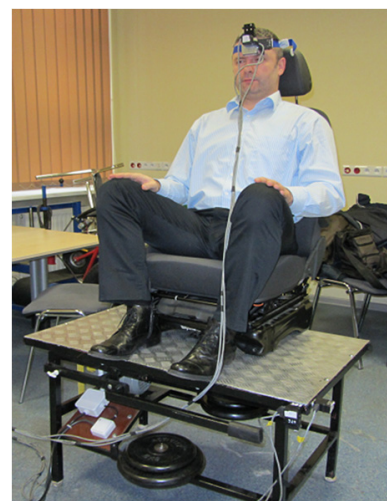

a)

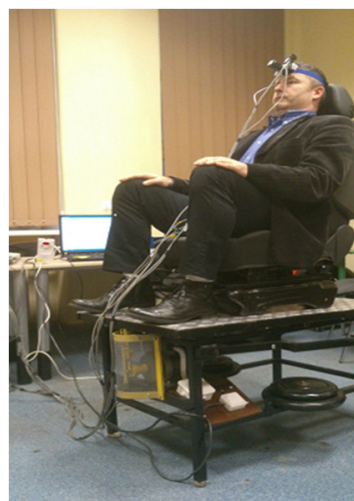

b)

Fig. 1. View of the test bench and the author during the tests

\section{Results}

The scope of the tests included a series of measurements for accepted measuring nodes for vibrations from $1 \mathrm{~Hz}$ to $35 \mathrm{~Hz}$, every $1 \mathrm{~Hz}$. The article presents sample results of registered vibration accelerations. As an example of the analysis of vibration propagation to the human body, the vibration patterns recorded in the measuring node were shown: the extinction plate (floor of the vehicle) and the head of the passenger. Due to the very large impact of vibrations affecting the human head on psychomotor skills and the sense of comfort of the driver, the assumed path of vibration propagation seems to be very important.

Figs. 2-4 present comparison signals of longitudinal, transverse and vertical vibrations recorded on the plate forcing the station (car floor simulator) and the head of the examined person. Next, in order to illustrate the type and degree of vibrations transmitted in a specific direction from the floor plate to the head of the examined person, the plate-head vibrations are shown in one graph (Fig. 5-7). 


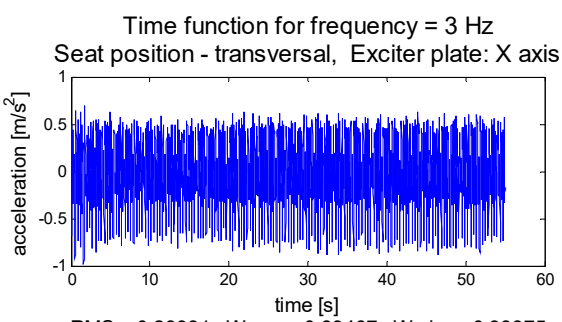

RMS $=0.28931$ Wmax $=0.69467$ Wmin $=-0.98375$ Exciter plate: $Y$ axis

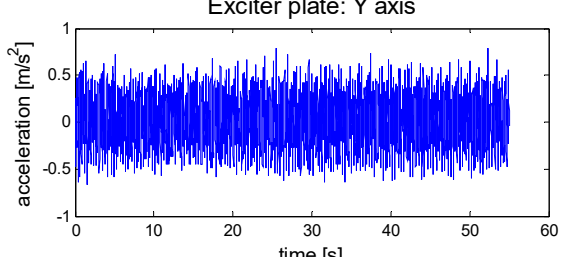

RMS $=0.24567$ Wmax $=0.78908$ Wmin $=-0.66533$ Exciter plate: $Z$ axis

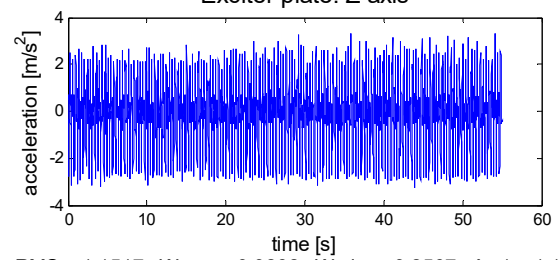

RMS $=1.1517$ Wmax $=3.3282$ Wmin $=-3.2567$ Aw1 $=1.1517$

a)
Time function for frequency $=3 \mathrm{~Hz}$ Seat position - transversal, Vibraion of head - $X$ axis

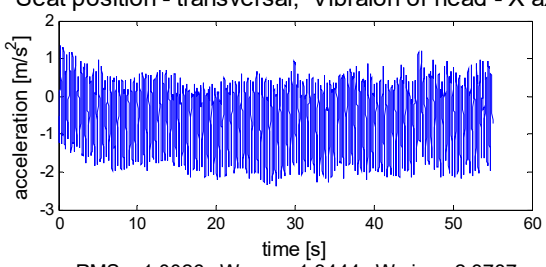

RMS $=1.0026$ Wmax $=1.3444$ Wmin $=-2.3787$ Vibraion of head - $Y$ axis

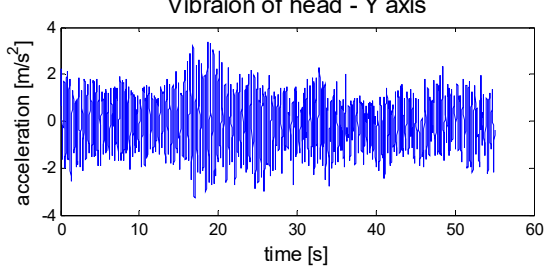

RMS $=1.1502$ Wmax $=3.3685$ Wmin $=-3.2472$ Vibraion of head $-Z$ axis

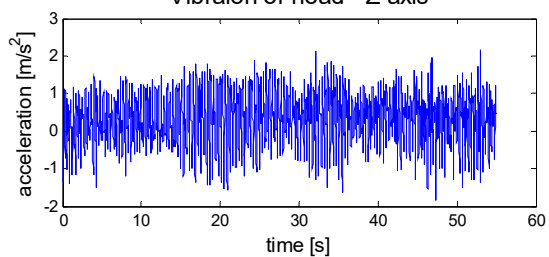

RMS $=0.71011$ Wmax $=2.1591$ Wmin $=-1.8417$ Aw2 $=1.6102$

b)

Fig. 2. Waveforms of orthogonal vibration, constant frequency ca. $3 \mathrm{~Hz}$ : a) exciter plate, b) head

Time function for frequency $=15 \mathrm{~Hz}$ Seat position - transversal, Exciter plate: $X$ axis

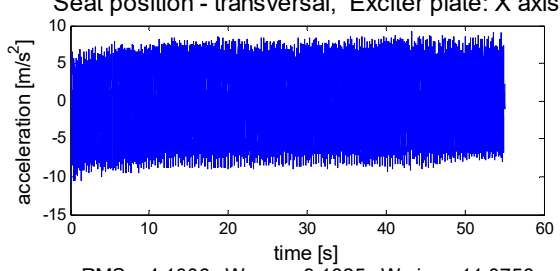

RMS $=4.1006$ Wmax $=9.1825$ Wmin $=-11.0758$ Exciter plate: $\mathrm{Y}$ axis

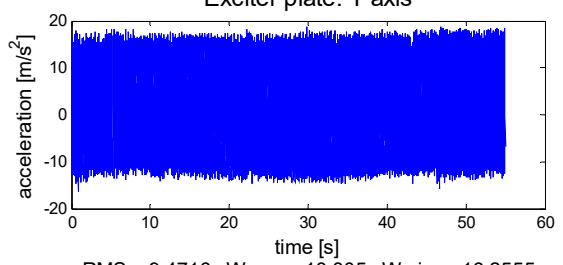

RMS $=9.4716$ Wmax $=18.805$ Wmin $=-16.2555$ Exciter plate: $Z$ axis

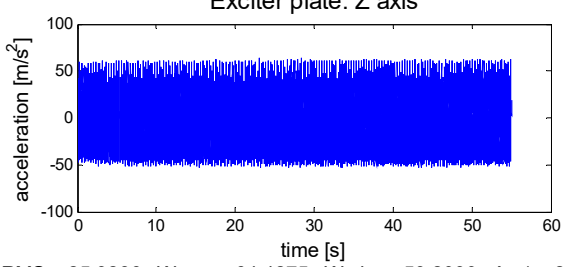

RMS $=25.3286$ Wmax $=64.4275$ Wmin $=-53.2039$ Aw1 $=25.3286$

a)
Time function for frequency $=15 \mathrm{~Hz}$ Seat position - transversal, Vibraion of head - $\mathrm{X}$ axis

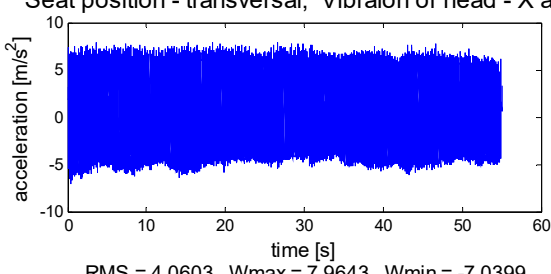

RMS $=4.0603$ Wmax $=7.9643$ Wmin $=-7.0399$ Vibraion of head - $Y$ axis

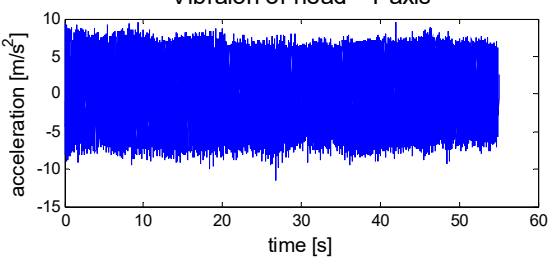

RMS $=4.6752$ Wmax $=9.6004 \quad W \min =-11.4522$ Vibraion of head $-Z$ axis

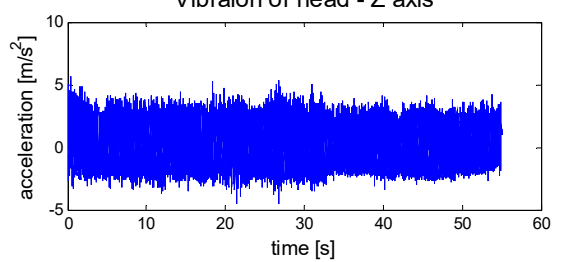

RMS $=1.5742 \quad W \max =5.661 \quad W \min =-4.5028 \quad A w 2=6.5452$

b)

Fig. 3. Waveforms of orthogonal vibration, constant frequency ca. $15 \mathrm{~Hz}$ : a) exciter plate, b) head 
Time function for frequency $=30 \mathrm{~Hz}$ Seat position - transversal, Exciter plate: $\mathrm{X}$ axis

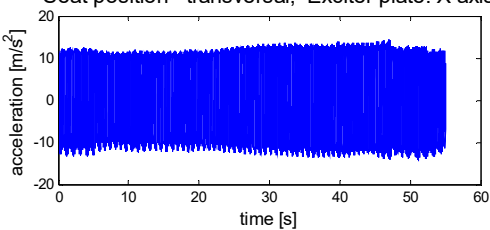

RMS $=9.5856$ Wmax $=14.3485$ Wmin $=-14.3389$ Exciter plate: $Y$ axis

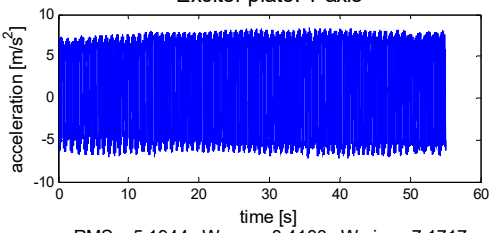

RMS $=5.1944$ Wmax $=8.4183$ Wmin $=-7.171$ Exciter plate: $Z$ axis

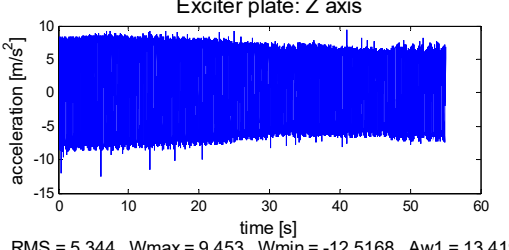

RMS $=5.344$ Wmax $=9.453$ Wmin $=-12.5168$ Aw1 $=13.4199$

a)
Time function for frequency $=30 \mathrm{~Hz}$

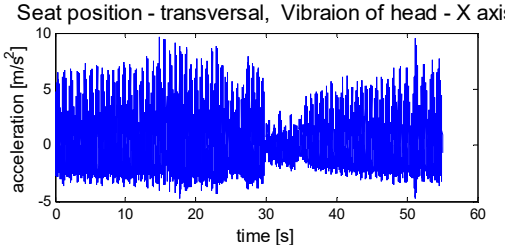

RMS $=2.3035$ Wmax $=9.6334$ Wmin $=-4.7528$ Vibraion of head - $Y$ axis

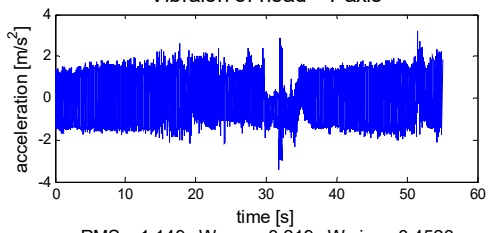

RMS $=1.149$ Wmax $=3.219$ Wmin $=-3.4523$ Vibraion of head $-Z$ axis

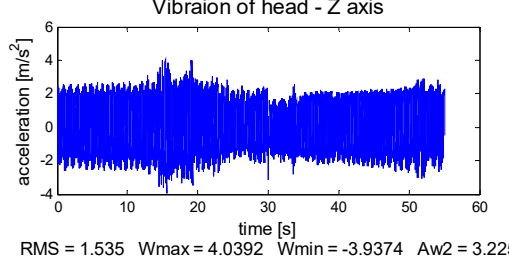

b)

Fig. 4. Waveforms of orthogonal vibration, constant frequency ca. $30 \mathrm{~Hz}$ : a) exciter plate, b) head

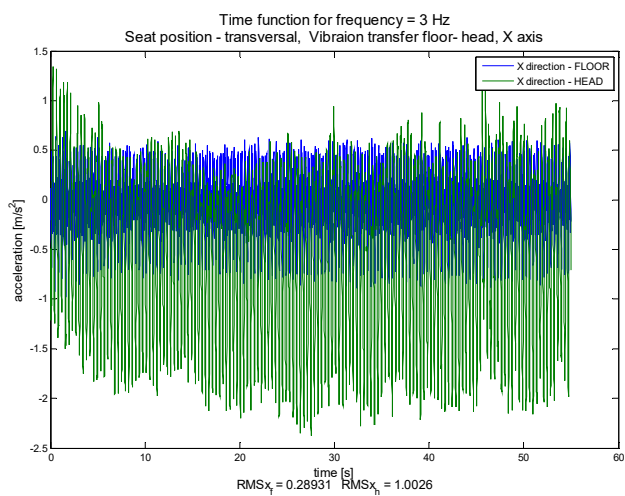

a)

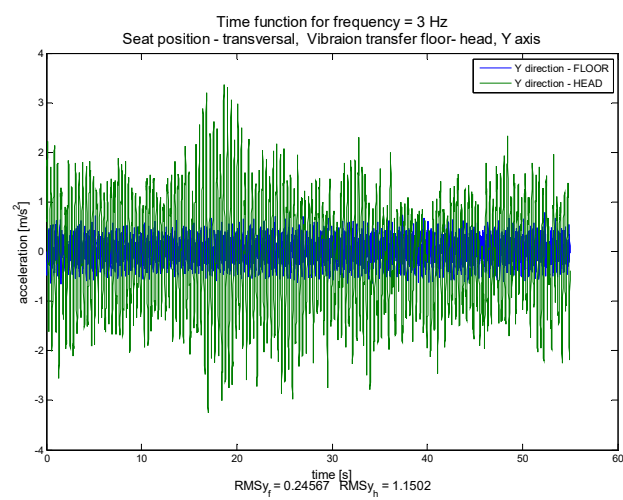

b)

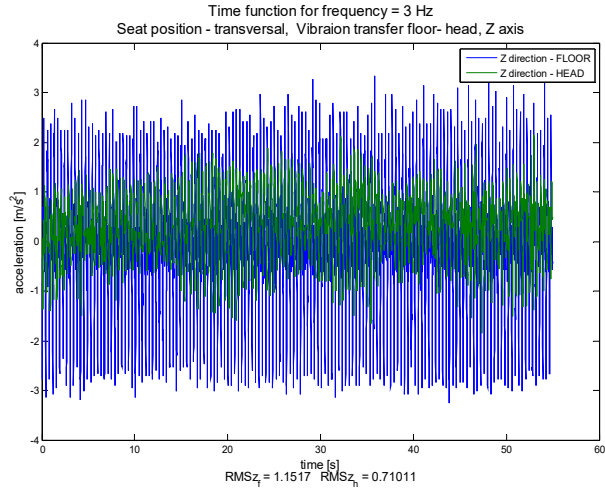

c)

Fig. 5. Comparison signals of longitudinal $(X)$, transverse $(Y)$ and vertical $(Z)$ vibrations of floor and the head of the examined person, constant frequency ca. $3 \mathrm{~Hz}$ 


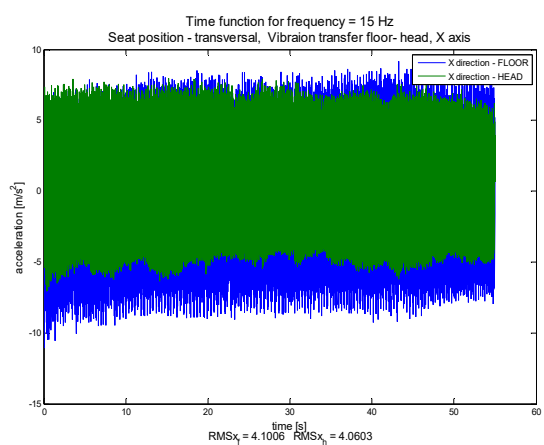

a)

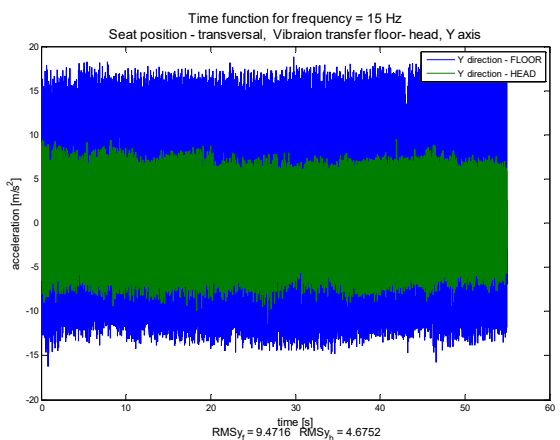

b)

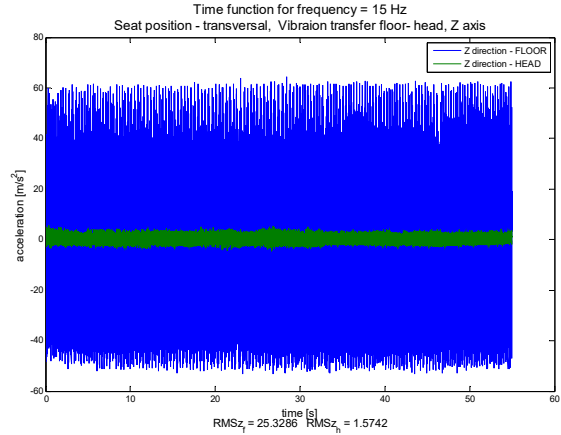

c)

Fig. 6. Comparison signals of longitudinal $(X)$, transverse $(Y)$ and vertical $(Z)$ vibrations of floor and the head of the examined person, constant frequency ca. $15 \mathrm{~Hz}$

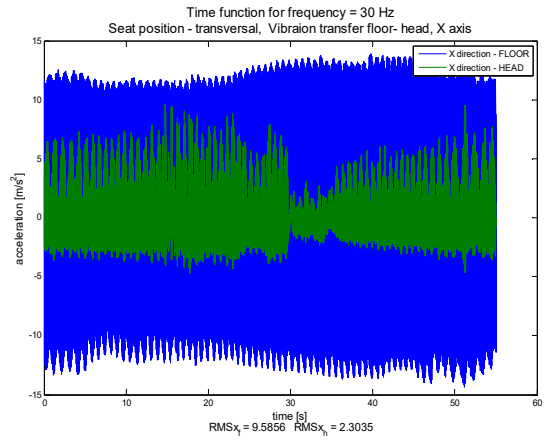

a)

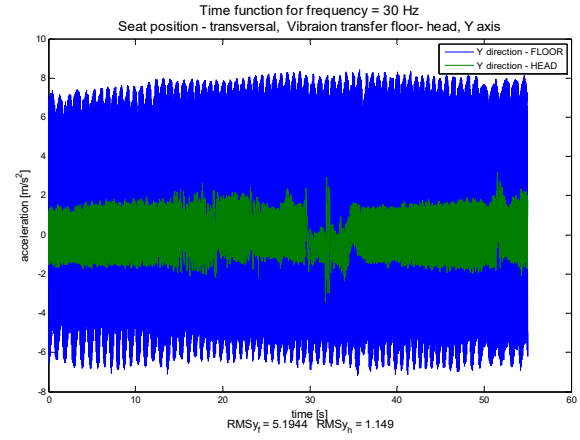

b)

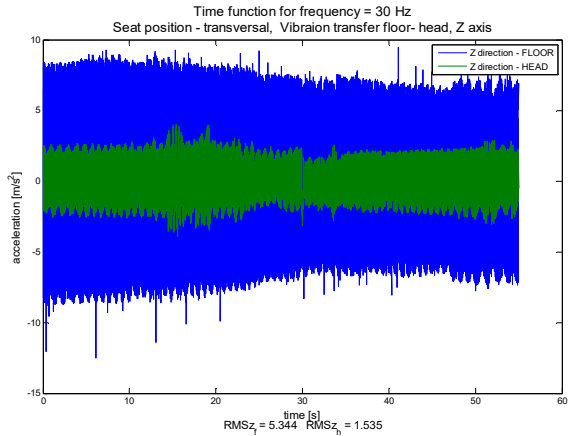

c)

Fig. 7. Comparison signals of longitudinal $(X)$, transverse $(Y)$ and vertical $(Z)$ vibrations of floor and the head of the examined person, constant frequency ca. $30 \mathrm{~Hz}$ 


\section{Conclusions}

The paper presents the results of preliminary tests, the aim of which was to analyze the propagation of vibrations forced by the movement of the vehicle floor on persons sitting in a car. According to the vibration mechanics, the path of propagation through the feet and lower limbs, the loins and the chest to the head was determined. This choice was dictated by an attempt to assess what vibrations may affect in the vicinity of vital human organs.

On the basis of the overall analysis of the test results, it was determined that the maximum values of recorded vibration accelerations on the head of the subjects were respectively: vertical vibrations $-12 \mathrm{~m} / \mathrm{s}^{2}$, transversal ca. $2.5 \mathrm{~m} / \mathrm{s}^{2}$ and longitudinal approx. $6 \mathrm{~m} / \mathrm{s}^{2}$. While the maximum vibrations recorded on the exciter plate were: vertical vibrations $-70 \mathrm{~m} / \mathrm{s}^{2}$, transversal vibrations around $2.5 \mathrm{~m} / \mathrm{s}^{2}$ and longitudinal vibrations - around $4 \mathrm{~m} / \mathrm{s}^{2}$. Due to research methodology and frequency scope of forced vibration it was noticed unsteady longitudinal, transverse movement of head for the higher frequencies, see at Fig. 4.

As part of further research, an analysis of vibration dynamics with the definition of frequency response and an attempt to assess the subjective and objective effects of vibration on human beings is assumed.

\section{References}

[1] Ortiz J. O., Betancur German R., Gomez J., et al. Detection of structural damage and estimation of reliability using a multidimensional monitoring approach. Proceedings of the Institution of Mechanical Engineers Part F - Journal of Rail and Rapid Transit, Vol. 232, Issue 4, 2018, p. 1021-1032.

[2] Gutierrez-Carvajal R. E., Betancur German R., Castaneda Leonel F., et al. A fractional Fourier transform-based method to detect impacts between the bogie and the car body of a railway vehicle: a data-driven approach. Proceedings of the Institution of Mechanical Engineers Part F - Journal of Rail and Rapid Transit, Vol. 232, Issue 1, 2018, p. 288-296.

[3] Gutierrez-Carvajal R. E., Betancur German R., Barbosa J., et al. Full scale fatigue test performed to the bolster beam of a railway vehicle. International Journal of Interactive Design and Manufacturing - IJIDEM, Vol. 12, Issue 1, 2018, p. 253-261.

[4] Chilinski B., Zawisza M. Analysis of bending and angular vibration of the crankshaft with a torsional vibrations damper. Journal of Vibroengineering, Vol. 18, Issue 8, 2016, p. 5353-5363.

[5] Mechanical Vibration and Shock: Evaluation of Human Exposure to Whole-body Vibration. Part 1, General Requirements: International Standard ISO 2631-1: 1997 (E), ISO, 1997.

[6] PN-EN 14253 Mechanical Vibrations. Measurement and Calculation of Occupational Exposure on Vibrations with General Effects on the Human Body for the Needs of Health Protection. Practical Guidelines, 2011.

[7] European Directive 2002/44/EC on the Minimum Health and Safety Requirements Regarding the Exposure of Workers to the Risks Arising from Physical Agents (vibration). European Commission, 2002.

[8] Griffin M. J. Handbook of Human Vibration. Academic Press, 2012.

[9] Burdzik R. The influence of the rotational speed of engine on vibrations transferred on vehicle construction. Scientific Journal of Silesian University of Technology, Series Transport, Vol. 72, 2011, p. 13-22.

[10] Konieczny L., Warczek J., Młynczak J., Zawisza M. Free vibration method for technical condition assessment of automotive shock absorbers. Diagnostyka, Vol. 18, 2017, p. 47-53.

[11] Warczek J. A study on exposing the driver of a commercial vehicle to mechanical vibration. Scientific Journal of Silesian University of Technology, Series Transport, Vol. 94, 2017, p. 229-238.

[12] Bovenzi M. Health risks from occupational exposures to mechanical vibration. La Medicina Del Lavoro, Vol. 97, Issue 3, 2006, p. 535-541.

[13] Zima B., Rucka M. Elastic wave propagation in diagnostics of self-drilling system of grouted anchors. Diagnostyka, Vol. 18, 2017, p. 31-36. 